\title{
Psychological and pedagogical aspects of education of tolerance in elementsry school
}

\author{
L. Cherednyk \\ State Berdyansk Pedagogical University \\ Corresponding author. E-mail: lidiya2772@i.ua
}

Paper received 15.04.19; Accepted for publication 29.04.19.

\section{https://doi.org/10.31174/SEND-PP2019-197VII79-03}

\begin{abstract}
The article reveals the peculiarities of the development of cognitive, motivational and emotional spheres among junior pupils, in particular their social status, ethnic and gender identity, the formation of a picture of the world, moral representations and moral behavior as a basis for the education of the tolerance of elementary school students.

Keywords: junior schoolchildren, education of tolerance, age features, social identity of junior school student, ethnic identity of junior schoolchildren, gender identity of junior schoolchildren.
\end{abstract}

Relevance of the topic: The processes of democratization and globalization that take place in the world from the end of the 20th and the beginning of the 21st century, which are associated with the collapse of totalitarian regimes in Europe and the creation of new independent states, the growth of integration processes and the intensive migration of the population, put a prominent place in the mission to educate young Generation with fundamentally new skills. On the one hand, it is an awareness of the necessity to preserve the unique peculiarities of each individual or a particular social group; on the other hand, a tolerant attitude to everything that goes beyond the limits of its usual perception is different from the already formed stereotype. Tolerance is the foundation of faith tolerance and peacefulness that prevents any kind of extremism that is significant for Ukraine as multinational and multi-religion country.

Problem statement: Development of human tolerance lasts throughout life. Psychologists distinguish five stages of development of tolerance: early (latent), empirical, collectivist, crisis and mature, the alternate change which means the transition of this feature-quality to a new stage of maturity, especially systems of psychosocial settings in relation to themselves and others. A. Furman and O. Shayuk, studying tolerance in the context of ontophēnomenological discourse, include to the collectivist stage raising of the tolerance of junior schoolchildren. If the main reference group for this age was the family for which the tolerance to her and her personal tolerance were determined by a system of relations with parents and close relatives, then at this stage the child faces the problem of subordinating their needs and wishes to the will of the external, non-family group, whose social guidelines often do not coincide with family attitudes and values.

Socio-psychological mechanisms that affect the personality development of tolerance, conformity is rightly attributed both internal and outside influence susceptibility requirements. Therefore, individual tolerance in this age formed mainly under the influence of samples and standards existing at group consciousness and group localized perception of the world [p.39-40]. ${ }^{1}$

\footnotetext{
${ }^{1}$ Furman AV Tolerance as an Object of Ontophēnomenological Discourse / AV Furman, O. Shyuk // Psychology and Society. 2015. - No. 3. - P. 31-61. - Access mode: http://nbuv.gov.ua/UJRN/Psis_2015_3_7.
}

Based on the information above, tolerance as a valuable component of the personality is part of a number of competences proclaimed by the Concept of a new Ukrainian school, in particular social and civic, as "the ability to work with others for the outcome, to prevent and resolve conflicts, to reach compromises," "respect for the law, respect for human rights and support for socio-cultural diversity ", awareness and expression in the field of culture as "a deep understanding of their own national identity as a basis for openness and respect for diversity and other cultural expressions " [p.12] $]^{2}$ Державним стандартом початкової освіти завдання формування «активної громадянської позиції на засадах демократії, поваги до прав i свобод людини, толерантного ставлення до оточуючих» покладається насамперед на громадянську та історичну освітні галузі The main taks of the state standard of primary education is forming of an "active civil position on the basis of democracy, respect for human rights and freedoms, tolerant attitudes towards others" relies firstly and foremost on the civil and historical educational branches $[\mathrm{p} .132]^{3}$. However, the education of tolerance in elementary school is impossible without taking into account the psychological and pedagogical features of junior schoolchildren.

Recent research and publications analysis: During the last decades, in modern psychological and pedagogical literature, some aspects of the education of tolerance of younger students were actively developed: tolerance structure of younger schoolchildren (M.Andreev, O.Bezkurovina, M.Gorvat, T.Gurova, V.Ternopilskaya and others); psychological characteristics and education of younger students (M.Ivanchuk, O.Oksenyuk); development of morality and moral consciousness (V. Zhigaryuk, R. Pavelko); formation of a social status (L.Moskalenko); dynamics of emotional and value attitudes (V.Kunishenko); role behavior (T. Yermolov); empathy and peculiarities of its development (I.Kogan); formation of the image of the world (I.Bushay); formation of interethnic tolerance (R.Zaredinova, O.Slyusarenko); gender culture (L.Vovk); legal culture (O.Kolosova) etc.

2 New Ukrainian School. Conceptual Principles of Reforming Secondary Education. - K., 2016. - 34 p.

3 State Standard of Elementary Education // New Ukrainian School: Foreword for Teacher. - K .: Litera-LTD, 2018. - S.128133.. 
The main goal of the article: identify psychopedagogical features primary school children as a basis for education in their tolerance based on analysis of current research.

Presentation of the main material of the research. Due to psychologists researches, the child develops the ability to initiative and conscious orientation in the system of social relations, the desire to determine their social status among others and to master its criteria; in personality consciousness for the first time a distinction is made between the social status of a person and his relation to himself in the past, present and future; the vectority of its own development, in pre-school age. Therefore, a sevenyear-old child can already experience himself in several sequences of events at the same time.

At the junior school age, the child's "I am in a society" is actively developing. It is connected with the mastery of social experience through the assimilation of tools, knowledge, symbols, the acquisition of fixed actions, their social essence, the development of ways to deal with objects, the ability to evaluate their own actions, try themselves to the outside, reflect on their actions and behavior (S. Rogacheva, F. Feldshtein). As a result, the social identity of the student is formed - awareness of the child's own social status of being student (cognitive component: "I am a schoolboy"), his significance and relevance in the hierarchy of social roles of the individual (emotional component: "It's important / not important that I am a schoolboy") ( L.Moskalenko). This contributes to the understanding of a child in common and different between them and representatives of other groups (ethnic, social, gender, etc.)

During the process of educating of younger schoolchildren, the peculiarities of each structural component of the emotional-value relation to educational activity are changing: there is an increase in the influence of the sociometric status of schoolchildren in the student group on their emotional and positive participation in the educational process; awareness of the reasons for these failures and the degree of satisfaction with their own academic achievements (V. Kutishenko). However, the attitude of the students to the student's social status is based not on meaningful and systematic knowledge, but mostly on the imitation of adults, and, consequently, is superficial and unstable (G.Lublinskaya). Being not able to objectively assess the complexity of a particular situation, junior students often determine their own, usually polar and nonappealing attitudes towards it, based on a separate, nonessential feature or detail that gives rise to contradictory assessment by the children of their own actions and deeds of others.

An important aspect of tolerance formation is the development of empathy. In the development of younger students spontaneously formed components of empathy, among them - the ability to direct and emotional empathy and compassion sensual imagery that appears in the form of emotional identification and understanding of moral conflicts. Reflexive-personal understanding causes considerable difficulties in the process of practical implementation due to the insufficient level of formation of the ability to personal reflection and the general low orientation to other people. Empathy formation among junior pupils should take place in two main directions: the de- velopment of personality's quality (emotional sensitivity) and the individual's ability to engage in empathy (compassion), which becomes the basis for the development of all components of empathy, primarily reflexivepersonality [p.17]. ${ }^{4}$

The motivational sphere of elementary schoolchildren varies from the domination of cognitive motives in the form of interest in the process of learning, to the various types of educational activities (writing, counting, reading) in the first class to the active interest in particular subjects, phenomena of nature and events from the lives of people in the second grade and differentiated interest in different content of knowledge, in particular to the actual, specific content of the third grade. Along with cognitive interests, social motives, aspirations for communication and joint activities with comrades begin to play a bigger role, as a result of which the value of judgments and assessments of classmates increases.

Junior school age is an important stage in the formation of the "I-concept" of personality, because at this age in the child's self-awareness, for the first time, a criterion such as the age-old social status of a person (T. Yermolov, I.Komohortseva, L.Moskalenko, T. Titarenko) is singled out, the ability to comprehend children's rights and responsibilities is intensively formed (N.Penkovsk, O. Khukhlaev), the internal position of the individual is developing (L. Bozhovich, N. Gutkina, T. Nezhnov). The student begins to self-identify as a subject of educational activity and subject of public relations: the role of external assessments increases; their content is become bigger, the accuracy is determined, and the regulatory function of the estimates increases. In general, the own "I-image" student creates according to social representations of moral, aesthetic and physical qualities of a person.

In elementary school, students acquire a number of features necessary for successful socialization: the restructuring of cognitive processes and the development of arbitrary attention, perception, memory; the transition from figurative to verbal-logical thinking; the formation of a system of specific concepts; development of selfregulation, formation of volitional characteristics; development of self-assessment on the basis of evaluation of reference persons (first of all, teachers); development of self-confidence, competence, if there is support from reference persons; development of uncertainty, self-doubt, loss of interest in learning - if the critical attitude of adults prevails; mastering the ability to read, write, count, and accumulate knowledge; increase in the level of homework skills (N. Golovanova).

The presence of these features allows the teacher to realize the main areas of education of tolerance: awareness of the principles of interdependence and complementarity as the leading in human relationships; bringing children to the cultures of different peoples of the world; raising respect for representatives of various socio-cultural groups at the level of family, class, school, communication environment, etc.

\footnotetext{
${ }^{4}$ Kogan I.M. Empathy and peculiarities of its development in children of elementary school age: author's abstract. Dis ... Cand. psychologist. Sciences: specialty 19.00 .07 - pedagogical and age psychology / Iryna Mikhailovna Kogan. - K., 2005. - 20 $\mathrm{p}$
} 
The moral values of junior pupils are still poorly conscious, unstable semantic entities based on the emotional and value relation to another person, the need to unite with others, generalize emotionally painted representations and knowledge about relationships on the basis of justice, humanity, responsibility, human dignity, that are manifested mainly in adaptive behavior-oriented behavior, norms given by adults [c. $]^{5}$. Moral rules of behavior are successfully assimilated by elementary school students, when the teacher not only reveals the meaning of the concept, but also demonstrates, on concrete examples, how they should be performed (to greet comrades, elders, to show respect for women, to sympathize with the patient, to show interest in the culture of other peoples, to respect traditions, etc.), carefully following the strict implementation of the proposed, involves the team to participate in the control of compliance with the rules.

During this period, a sense of self-esteem develops, which manifests itself in an agitated response to any humiliation of the individual and the positive emotional experience of recognizing certain positive qualities, moral feelings: a sense of friendship, sociability, duty, humanity, tolerance. The values that were mentioned above, are not yet formed at the level of the concepts in the elementary school, but the children already have ideas related to eternal values and their antipodes (kindness - cruelty, honesty - dishonesty); about national values (national dignity, love of mother tongue, respect for national holidays and traditions); about community and family values (respect for the law, care for the elderly in the family, hospitality, etc.); some values of personal life (sense of humor, cheerfulness, hard work). So, the cognitive aspect of tolerance is the most important for the younger students,.

N. Yevtushenko believes that students with an adequate level of tolerance are prevalent in the elementary school: they know and respect the national culture, accept the cultural differences of other people, successfully interact in the team, can withstand intolerant relationships, can detect a culture of tolerant behavior and communication. Among the features of junior school age, which can be defined as the basis for the education of students' intercultural tolerance, the researcher singles out the development of ethical concepts and concepts, the internalization of moral and ethical values; the formation of feelings (friendship, friendship, duty), further differentiation of emotional vulnerability; development of self-regulation, formation of volitional characteristics; mastering the ability to read, write, accumulate knowledge that affects the formation of the worldview [p.229-230].

However, studies M.Horvat indicates that tolerance education in primary school children is not sufficient: low characteristic for $80.2 \%$ of subjects below the average level is typical for $14.8 \%$ of the respondents. The smallest number of junior pupils $(5.0 \%)$ is distinguished by the average level of education of the specified quality. The conducted research revealed the results that characterize the low level of information-cognitive and instrumental-

${ }^{5}$ Fedorova M.A. Content characteristic of moral values of junior schoolchildren / M.A. Fedorova / Youth and market. Drohobych, 2016. - P. 56-62. - Access mode: http://eprints.zu.edu.ua/22538/1/2016_87.PDF.. behavioral criterion and partial level, lower than average, - the motivational-value criterion.

The reasons for the low level of tolerance for elementary school students, according to the researcher, are the lack of knowledge about the norms of morality and universal values and the ability to use them in various activities; the lack of established skills and habits of tolerant behavior, conscious actions and actions based on constructive methods of interaction, equal communication, ability to listen to another, to possess oneself; the inability to promote the unity of the collective, the implementation of tolerant values in a situation of free choice [p.9]. ${ }^{6}$

T.Gurova determines the features of the tolerance qualities of junior pupils, based on the components of its structures, namely: the speed and stability of the positive emotional reaction of the junior schoolboy to the presence of cultural, religious, national or ethnic differences (psycho-physiological component); ability to react positively, understand and adequately perceive external information that differs from its own positions; the ability to sense the significance of the difference and respond accordingly to it; the ability to recognize the right to exist in a different position in views, beliefs and traditional representations; Ability to emotionally empathize, benevolently and with patience to relate to feelings and manifestations of other people (emotional-empathic component); interest in mutual exchange of information with representatives of other cultural traditions and beliefs; the desire of a younger student to independently learn a new, unfamiliar, acquire knowledge in case of finding differences and use them in their own life; the ability to adapt to the excellent position of the interlocutor; orientation on overcoming conflict situations in communication (motivational-value component); friendly and courteous attitude of the junior pupil to representatives of other religious, national or cultural differences at the time of communication; the ability to avoid conflicts, as well as prevent the aggravation of controversial moments during interaction; the ability to conduct an open constructive dialogue in order to enrich their own experience, learn something new; the formation of knowledge about the ability to avoid conflict situations, to prevent the aggravation of controversial moments in the discussion; the ability to find common in communication without emphasizing differences in views and beliefs; knowledge of the provisions of ethics, understanding of the role of morality in communication (ethical and communicative component); understanding of the relativity of truth; the presence of the installation to change its position in case of convincing arguments from the other; awareness and recognition of an excellent position in the views of classmates; availability of flexible and critical comprehension of new information (cognitive component); the formation of readiness for positive interaction, the availability of ready models of tolerant behavior, the presence of a positive reaction to differences; manifestations of a benevolent and interested attitude in the course of communication and encounter with representatives of

6 Gorvat M.V. Raising tolerance in junior pupils in an interactive pedagogical communication: Author's abstract. Dis ... Cand.Ped.Science: Specialty 13.00.07 - Theory and Methodology of Education / Marianna Vasylivna Horvat. Uman, 2014. - 19p.. 
other cultural traditions a behavioral component (behavioral component); the formation of skills to analyze the results of interaction with those with whom is communicating; the ability to realize their own emotions, thoughts, words, actions and ways of interaction with another mentality; ability to make judgments, based on moral values (reflexive component) [p.75-77]. ${ }^{7}$

Analyzing the state of development of psychological and social motivation of junior schoolchildren, modern researchers have come to the conclusion that there are certain tumors in pupils, which are prerequisites for the development of certain types of tolerance in them. Thus, J. Piazhe also singled out three stages in the formation of ethnic identity: in 6-7 years, the child acquires the initial (fragmentary, non-systematic) knowledge of his ethnic affiliation; From the age of 8 - 9, the child is already clearly identifying himself with members of his ethnic group, the emergence of national feelings; In the younger adolescence (10-11 years), ethnic identity is formed entirely: the child is aware of the ethnic identity of not only his own people, but also others. On the basis of scientific and psychological literature, O. Slyusarenko, O. Kadaner, came to the conclusion that the beginning of diffuse identification with the ethnic group most children find in children 3 - 4 years old, that the "realized" ethnic identity reaches the child in the younger adolescence, when the reflection itself is of paramount importance to a person [p.541 ${ }^{8}$. At junior school age, there is a significant increase in ethnic knowledge, not a simple repetition, and the systematization of information received from adults. It is at this age that there are prerequisites for tolerance as a personality, as younger students begin to realize their ethnic identity and understand ethnic differences.

The main psychological neoplasms of the junior school age (the arbitrariness of psychological processes, the inner plan of action, the ability to organize educational activity, reflection, etc.) actively contribute to the formation and development of legal consciousness, and on its basis - and the legal tolerance of students.

A younger student, observing the consequences of observance or violation of norms, understands their content more easily and applies them to themselves. The child not only understands the norm, but relates it to a certain category ("good" - "bad"), tends to give an assessment. In the early school years the development of moral and legal assessments associated with the evaluation of actions adult children. They have standards - samples that contain generalized ideas about positive and negative behavior in life situations (O. Kolosova).

L.Vovk and V.Mukhina investigated the pedagogical conditions for the formation of the gender culture of younger schoolchildren, revealed the essential features of this pedagogical phenomenon, which give rise to the education on the basis of gender tolerance. She notes that

7 Gurova T.Yu. Analysis of Tolerance Structure of Junior Student / T.Yu.Gurova // Spirituality of Personality: Methodology, Theory and Practice. - 2010 - 5 (40). - P. 70-78..

8 Slyusarenko O. S. Preparation of future primary school teachers for the education of interethnic tolerance of junior pupils / O. S. Slyusarenko, O. V. Kadaner / / Young Scientist. 2017. - No. 2. - P. 540-543. - Access mode: http://nbuv.gov.ua/UJRN/molv_2017_2_128. younger schoolchildren are not only aware of their affiliation to a particular gender, but they seek to establish themselves as a woman or a man, although there is no pronounced fixation on the gender difference at this age. The formation of gender identity, and hence of gender tolerance, happens not only through the learning of subjects, but also through understanding the world around us, especially gender relations in the family (the gender role of the father, the mother and father's parenting style, the gendered education standards, the presence of gender stereotypes, are reflected in the peculiarities of the parents' reaction to the success of children, the advice given by parents in different situations, the types of activities that involve children, the choice of toys that buy, etc.) [p.44-46]. ${ }^{9}$

As a result, L.Vovk displays the typical age-specific features of the gender identity of junior pupils: the need for self-affirmation as a representative of a certain gender in the relationship; involuntary embedding into the system of gender values; imposing images from the outside world; stability of stereotypes; moral benchmarks for gender socialization; gender-segregation and convergence; the formation of sex subcultures; the emergence of "unwritten rules" and communication in the "limit allowed"; sexual confrontation (rejection of non-standards of behavior for their gender) and others [p.53]. ${ }^{10}$

Conclusions. The education of tolerance in elementary school is based on the principle of the correspondence of educational influences on the pupil's age characteristics and should take into account the following features of the junior school age: awareness of the students' own social status, understanding of other personal statuses (ethnic, age, gender, etc.); development of emotional sensitivity and ability to empathic interaction (compassion) as an emotional basis of tolerance; expansion of the motivational sphere of students due to social motives and the appearance of interest in manifestations of another; the presence of basic moral ideas for understanding the values of the culture of another; awareness of the multifaceted nature of the world, including physical, gender and ethnocultural microcosm; the ability to evaluate and reason for self-assessment; assimilation by students of rules of moral behavior; positive reaction of younger schoolchildren to the presence of cultural, national or religious differences; interest in the exchange of information, which provides grounds for the organization in the elementary school of educational work on the development of students' tolerance. The conducted research does not exhaust the multifaceted theoretical and practical search for the solution of the problem. Promisingly, we consider the study of methodical support for the education of tolerance of junior schoolchildren, which follows from the specific

9 Vovk L.M. Pedagogical conditions for the formation of the gender culture of junior pupils in the educational activity of the elementary school: Dis.cand.ped. Sciences: specialty 13.00.07 theory and methodology of education / Lilia Nikolayevna Vovk. - K., 2017. - 219 p.

10 Vovk L.M. Pedagogical conditions for the formation of the gender culture of junior pupils in the educational activity of the elementary school: Dis.cand.ped. Sciences: specialty 13.00.07 theory and methodology of education / Lilia Nikolayevna Vovk. - K., 2017. - 219 p. 
features, and the specification of the influence of the ageold peculiarities of junior pupils on the education of cer- tain types of tolerance.

\section{REFERENCES}

1. Vovk L.M. Pedagogical conditions for the formation of the gender culture of junior pupils in the educational activity of the elementary school: Dis.cand.ped. Sciences: specialty 13.00.07 - theory and methodology of education / Lilia Nikolayevna Vovk. - K., 2017. - 219 p.

2. Gorvat M.V. Raising tolerance in junior pupils in an interactive pedagogical communication: Author's abstract. dis Cand. ped Sciences: specialty 13.00.07 - theory and methodology of education / Marianna Vasylivna Horvat. - Uman, 2014. - 19 p.

3. Gurov T.Yu. Analysis of Tolerance Structure of Junior Student / T.Yu. Gurova // Spirituality of personality: methodology, theory and practice. - 2010 - 5 (40). - P. 70-78.

4. State standard of elementary education // New Ukrainian school: a preface for a teacher. - K .: Litera-LTD, 2018. p.128-133.

5. Evtushenko N.A. Age features of elementary school students in the context of cultivating intercultural tolerance / N.A.Yevtushenko // Theoretical and methodological problems of education of children and youth. 2014.-Vip. 18 (1). P. 223-232. - Access mode: http://nbuv.gov.ua/UJRN/Tmpvd_2014_18\%281\%29_27.

6. Zareidinova E.R. Problems of formation of interethnic tolerance in primary school students (psychological and pedagogical aspect) / E. R. Zareidinova // Postmetodyka. - 2009. - No. 2. - P. 41-43.
7. Kogan I.M. Empathy and peculiarities of its development in children of elementary school age: author's abstract. dis Cand. psychologist. Sciences: specialty 19.00.07 - pedagogical and age psychology / Iryna Mikhailovna Kogan. - K., 2005. - 20 p.

8. New Ukrainian School. Conceptual Principles of Reforming Secondary Education. - K., 2016. - 34 p.

9. Slyusarenko O. S. Preparation of future primary school teachers for the education of inter-ethnic tolerance of junior pupils / O. S. Slyusarenko, O. V. Kadaner / / Young Scientist. 2017. - No. 2. - P. 540-543. - Access mode: http://nbuv.gov.ua/UJRN/molv_2017_2_128№ 2. - P. 540543

10. Fedorova M.A. Content characteristic of moral values of junior schoolchildren / M.A. Fedorov / Molod i Rynok. Drohobych, 2016. - P. 56-62. - Access mode: http://eprints.zu.edu.ua/22538/1/2016_87.PDF.

11. Furman A.V. Tolerance as an Object of Ontophēnomenological Discourse / A.V. Furman, O. Shyuk // Psychology and Society. - 2015. - No. 3. - P. 31-61. - Access mode: http://nbuv.gov.ua/UJRN/Psis_2015_3_7. 